\title{
A Rare of Klinefelter Syndrome with Normal Phenotype: A Case Report
}

\author{
Zhainagul Kozhabek ${ }^{1}$, QiongZhen Zhao ${ }^{2}$, Pang Min $^{3}$
}

\begin{abstract}
Klinefelter syndrome (KS) is a genetic condition that results from male with one or more extra copy of the X chromosome. The primary features are infertility and small, poorly functioning testicles. Symptoms also include greater height, less body hair, weaker muscles, poor coordination, enlarged breast tissue, and less interest in sex. We present the case of a 36-year-old man who is KS with normal clinical and laboratory phenotype, which is a very rare finding in this syndrome. Most men with KS are infertility, they produce little or no sperm. Assisted reproductive procedures may help some men with KS to father a child. But the necessity of PGD during assisted reproductive treatment has always been a controversial topic. In this case, we examined five blastocysts of patient, two of them with abnormal karyotype and other three were normal. Therefore, it is necessary to carry out preimplantation genetic diagnosis for KS patients before implantation, even though their phenotypes are normal. Keywords: Infertility, Intracytoplasmic sperm injection, Klinefelter syndrome, Preimplantation genetic diagnosis. International Journal of Infertility and Fetal Medicine (2021): 10.5005/jp-journals-10016-1225
\end{abstract}

\section{INTRODUCTION}

Klinefelter syndrome (KS) was first reported by Harry Klinefelter in 1942. ${ }^{1}$ Until 1959, Jacobs and Strong found that chromosomal karyotypes of these patients are carry one or more extra $X$ chromosome. ${ }^{2}$ The reason for this aberration is that non-disjunction of gametes during meiosis or of zygotes at the early stage of mitosis. ${ }^{3}$

The physical development of patients in fetuses, newborns, and childhood is somewhat different from normal people, but not very obvious. ${ }^{4}$ After puberty, the physical traits of the syndrome become more evident. Presenting as small testicles; taller than average; rare body hair (beard, pubes); decreased bone density; about 56-88\% of patients have female-like breast development. ${ }^{5}$ With growth, testosterone and inhibin $\mathrm{B}$ (INH-B) levels decrease, luteinizing hormone (LH), and follicle-stimulating hormone (FSH) levels increase significantly. Spermatotubule degeneration accelerates and germ cells gradually disappear. By adulthood, INH-B could not be detected, the seminiferous tubules were atrophic, there have been only small and immature Sertoli cells, no germ cells and sperm, and Riddle cells proliferated. ${ }^{2}$

Azoospermia and infertility are the primary features of KS. Previously thought that KS patients were completely azoospermic. But later histological research about testicular biopsy found the existence of focal spermatogenesis in some KS patients. Methods of reproductive medicine such as testicular sperm extraction (TESE) technics combined with intracytoplasmic sperm injection (ISCl) have made it possible for KS patients to be the genetic father of their children.

The fertility of KS patients is due to the normal cloning of testicular cells. ${ }^{6}$ Spermatogenesis is positively correlated with androgen level in KS patients. ${ }^{7}$ In other words, KS patients with normal levels of free testosterone have a better gonadal function, androgen production in testis related to spermatogenic function. ${ }^{8,9}$

Over 100 children have been born worldwide using IVF technology with surgically removed sperm from KS patients, all
${ }^{1}$ Saken Seifullin Kazakh Agrotechnical University, Nur-Sultan, Kazakhstan; Reproductive Medicine Center, XinJiang JiaYin Hospital, Urumchi, China

${ }^{2,3}$ Reproductive Medicine Center, XinJiang JiaYin Hospital, Urumchi, China

Corresponding Author: Zhainagul Kozhabek, Saken Seifullin Kazakh Agrotechnical University, Nur-Sultan, Kazakhstan; Reproductive Medicine Center, XinJiang JiaYin Hospital, Urumchi, China, Phone: +77788095132, e-mail: jaynahojabek@yahoo.com

How to cite this article: Kozhabek Z, Zhao QZ, Pang M. A Rare of Klinefelter Syndrome with Normal Phenotype: A Case Report. Int J Infertil Fetal Med 2021;12(3):77-79.

Source of support: Nil

Conflict of interest: None

of them are healthy with a normal karyotype. Greco et al. consider the possible reason is the chromosome composition of KS patients spermatogenic cells are $46 \mathrm{XY}$, rather than $47 \mathrm{XXY}$, so the sperm may also be normal. They concluded that KS does not increase the incidence of chromosome abnormalities in offspring. ${ }^{10,11}$

Skakkebak and Vidal analyzed the meiotic preparations and synaptonemal complex spreads of XXY and XXY/XY inlaid patients and found that some $X X Y$ cells could reach the primary spermatocyte stage. Another study confirmed this finding by ejaculated sperm aneuploidies and intratesticular germ cells in 47 XXY men, suggesting that XXY germ cells can complete meiosis. Consequently, men with KS produce a higher number of sperm aneuploidy, particularly of sex chromosomes.

Staessen ${ }^{12}$ was used fluorescence in situ hybridization (FISH) to detect the embryos of KS patients. The results showed that $46 \%$ of the embryos were abnormal, which was significantly higher than that of the control group. The abnormal rate of sex chromosome was $13.2 \%$, for autosomes, this is only significant on chromosome 18 and chromosome 21.

(c) Jaypee Brothers Medical Publishers. 2021 Open Access This article is distributed under the terms of the Creative Commons Attribution 4.0 International License (https://creativecommons.org/licenses/by-nc/4.0/), which permits unrestricted use, distribution, and non-commercial reproduction in any medium, provided you give appropriate credit to the original author(s) and the source, provide a link to the Creative Commons license, and indicate if changes were made. The Creative Commons Public Domain Dedication waiver (http://creativecommons.org/publicdomain/zero/1.0/) applies to the data made available in this article, unless otherwise stated. 


\section{Case Description}

The patient was 36-year-old man with a height of $186 \mathrm{~cm}$. His intelligence quotient (IQ) was normal level, body hair was normal, testicular volume were $14 \mathrm{~mL}$ (right) and $12 \mathrm{~mL}$ (left), respectively, no hypospadias, normal laryngeal prominence and voice, no feminized breasts. The sex hormone levels were detected, with results of FSH $3.91 \mathrm{mIU} / \mathrm{mL}$ (normal range: 1.27-13.55 $\mathrm{mlU} / \mathrm{mL}$ ), and LH $2.04 \mathrm{mIU} / \mathrm{mL}$ (normal range: $1.24-8.62 \mathrm{mIU} / \mathrm{mL}$ ), the levels of FSH and LH were normal at different time points. Testosterone was $4.45 \mathrm{mIU} / \mathrm{mL}$ (normal range: $1.75-7.81 \mathrm{mIU} / \mathrm{mL}$ ), semen volume was 1.8 (normal range: $>1.5 \mathrm{mlU} / \mathrm{mL}$ ), sperm concentration was 57.10 (normal range: $>15 \mathrm{mlU} / \mathrm{mL}$ ), sperm count was $102.78 \times 10^{9}$ (normal range: $>39 \times 10^{9}$ ), total vitality was 64.25 (normal range: $>40 \mathrm{mIU} /$ $\mathrm{mL}$ ), forward motile sperm was 58.50 (normal range: $>32 \mathrm{mlU} / \mathrm{mL}$ ), normal morphological active sperm was 14 (normal range: $>10 \mathrm{mIU} /$ $\mathrm{mL}$ ), serum free thyroxine was 1.54 (normal range: 0.93-1.7 mIU/ $\mathrm{mL}$ ), bone density was normal (Table 1).

Karyotyping was performed following peripheral blood lymphocyte culture. A total of 100-200 metaphase cells were analyzed by the G-banding method. Chromosomal analysis revealed that the patient's karyotype is $47 \mathrm{XXY}$ (Fig. 1) and highthroughput sequencing also indicated consistent results (Fig. 2). Before the chromosomal abnormality test, the patient himself or his family did not found any abnormality about him. The patient's phenotype and indicators were normal and had never received any

Table 1: Results of related hormones and semen test

\begin{tabular}{lll}
\hline Test item & Numerical value & Reference range \\
\hline FSH $(\mathrm{mlU} / \mathrm{mL})$ & 3.91 & $1.27-13.55$ \\
$\mathrm{LH}(\mathrm{mlU} / \mathrm{mL})$ & 2.04 & $1.24-8.62$ \\
Testosterone $(\mathrm{mlU} / \mathrm{mL})$ & 4.45 & $1.75-7.81$ \\
Semen volume $(\mathrm{mlU} / \mathrm{mL})$ & 1.8 & $>1.5$ \\
Sperm concentration $(\mathrm{mlU} / \mathrm{mL})$ & 57.10 & $>15$ \\
Sperm count & $102.78 \times 10^{9}$ & $>39 \times 10^{9}$ \\
Total vitality $(\mathrm{mlU} / \mathrm{mL})$ & 64.25 & $>40$ \\
Forward motile sperm $(\mathrm{mlU} / \mathrm{mL})$ & 58.50 & $>32$ \\
Normal morphological active & 14 & $>10$ \\
sperm $(\mathrm{mlU} / \mathrm{mL})$ & & \\
Serum free thyroxine $(\mathrm{mlU} / \mathrm{mL})$ & 1.54 & $0.93-1.7$ \\
\hline
\end{tabular}

hormone therapy. He has been married for 3 years. The patient was hospitalized due of his wife's fallopian tube is blocked. We obtained five blastocysts using ICSI. After genetic counseling, the couple agrees to undergo PGD to their blastocysts. According to PGD results, three blastocysts are normal and one was $\mathrm{X}$ chromosome deletion, another was trisomy 18 (Fig. 3). We implanted an embryo with a normal karyotype and higher morphology score. At the 25 gestational age, amniotic fluid aspiration showed that fetal karyotype was normal.

\section{Conclusion}

The patient's karyotype is $47 \mathrm{XXY}$, which is KS. The patient's phenotype, hormone level, sperm, and reproductive system are normal, testicular biopsy and semen analysis showed that hyalinization and tubular were all normal, Sertoli and Leydig cells have appeared normal too. The life expectancy of KS patients is 11.5 years shorter than that of normal people. ${ }^{13}$ Patients could die of a series of complications, such as diabetes, lung disease, epilepsy, cardiovascular disease, intestinal vascular dysfunction, etc. The patient with normal clinical and laboratory features at age 36 , without any predicted complication signs like other patients

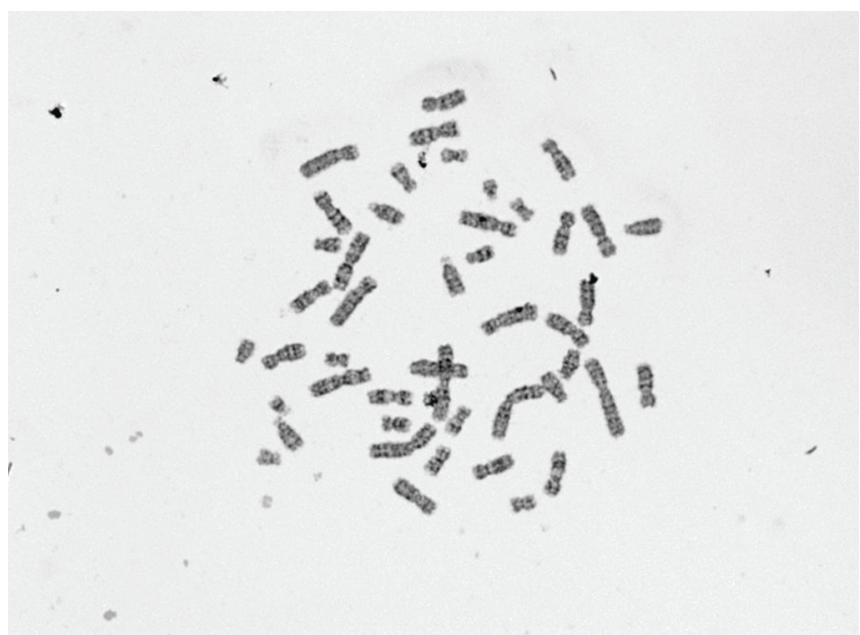

Fig. 1: Results of routine karyotyping. One of the metaphase cells analyzed using the G-banding method

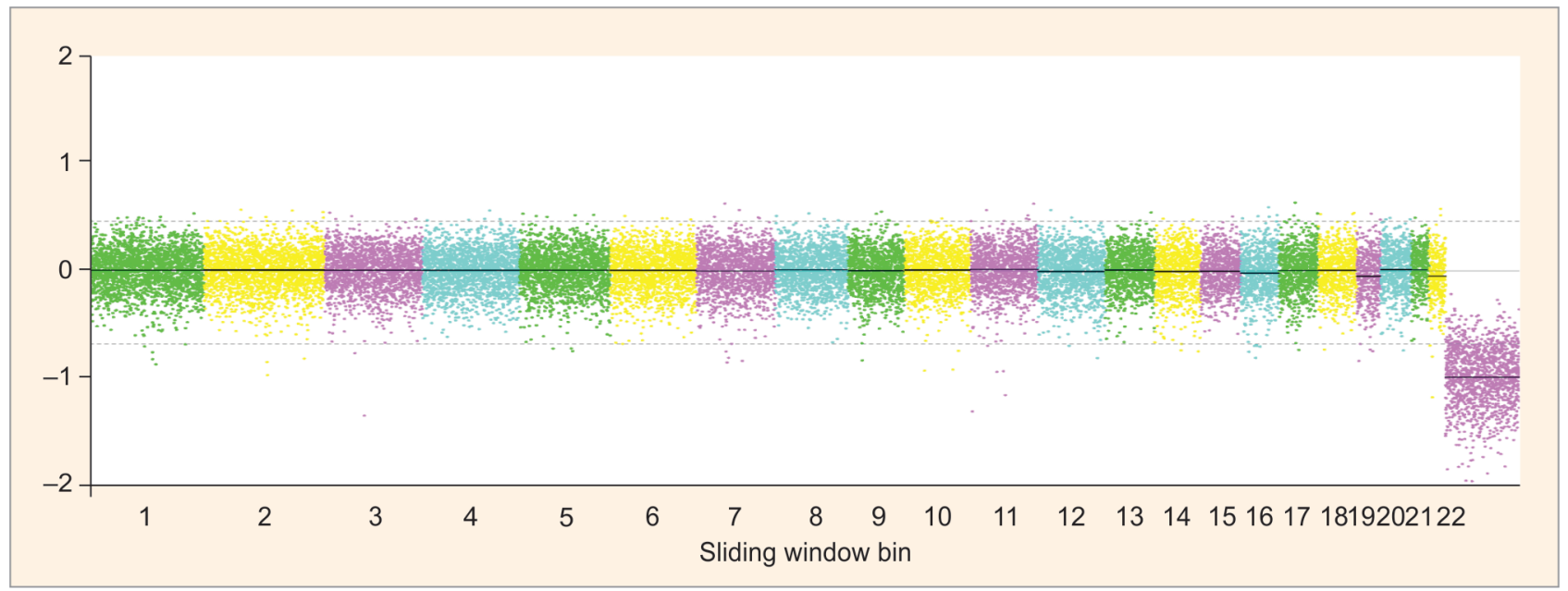

Fig. 2: Detection of Y chromosome microdeletion using high-throughput sequencing technology 


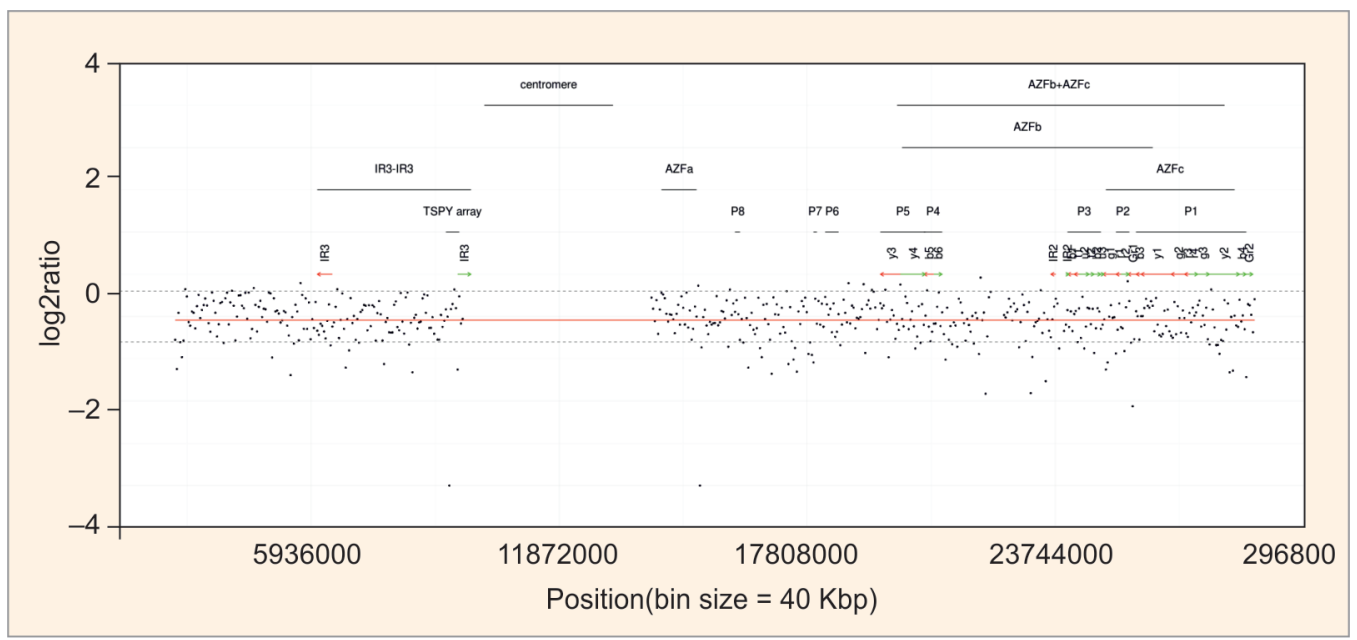

Fig. 3: PGD results of two abnormal embryos

suffered in same or younger age, which is a very rare finding in this syndrome. Using PGD technology, we analyzed five blastocysts. Two of them with abnormal karyotype which were trisomy 18 and $\mathrm{X}$ chromosome deletion, respectively, and the other three were normal.

There are many controversies about the incidence of fetal chromosomal abnormalities and the clinical value of preimplantation genetic diagnosis (PGD) on KS. We strongly emphasize the necessity of PGD for KS patients before implantation, even though their phenotypes are normal. Although most offspring of KS patients with normal karyotypes, there is still the possibility that their embryos have abnormal karyotypes, not only sex chromosome abnormality but also autosomal abnormality.

Moreover, considering this patient's situation and previous research, when KS patients are diagnosed in childhood, they could not be treated with testosterone without a clear prognosis for future sexual development. They should not start the treatment until testicular failure is clearly proved.

\section{References}

1. Klinefelter HF, Reifenstein EC, Albright F. Syndrome characterized by gynecomastia, aspermatogenesis without A-leydigism, and increased excretion of follicle-stimulating hormone. J Clin Endocrin Metabol 1942;2(11):615-623. DOI: 10.1210/jcem-2-11-615.

2. Jacobs PA, Strong JA. A case of human intersexuality having a possible XXY sex-determining mechanism. Nature 1959;183(4657):302-303. DOI: 10.1038/183302a0.

3. Lanfranco F, Kamischke A, Zitzmann M, et al. Klinefelter syndrome. Lancet 2004;364(9430):273-283. DOI: 10.1016/S0140-6736(04) 16678-6.

4. Lahlou N, Fennoy I, Carel J-C, et al. Inhibin B and anti-Müllerian hormone, but not testosterone levels, are normal in infants with nonmosaic Klinefelter syndrome. J Clin Endocrinol Metab 2004;89(4):1864-1868. DOI: 10.1210/jc.2003-031624.

5. Wikström AM, Bay K, Hero M, et al. Serum insulin-like factor 3 levels during puberty in healthy boys and boys with Klinefelter syndrome. J Clin Endocrinol Metabol 2006;91(11):4705-4708. DOI: 10.1210/jc.20060669.

6. Foss GL, Lewis FJW. A study of four cases with Klinefelter's syndrome, showing motile spermatozoa in their ejaculates. J Reprod Fertil 1971;25(3):401-408. DOI: 10.1530/jrf.0.0250401.

7. Aksglæde L, Wikström AM, De Meyts ER, et al. Natural history of seminiferous tubule degeneration in Klinefelter syndrome. Human Reproduct Update 2005;12(1):39-48. DOI: 10.1093/humupd/ dmi039.

8. Wikstr M, Hoei-Hansen AM, Dunkel CE, et al. Immunoexpression of androgen receptor and nine markers of maturation in the testes of adolescent boys with Klinefelter syndrome: evidence for degeneration of germ cells at the onset of meiosis. J Clin Endocrinol Metabol 92(2):714-719. DOI: 10.1210/jc.2006-1892.

9. Sciurano RB, Luna Hisano CV, Rahn MI, et al. Focal spermatogenesis originates in euploid germ cells in classical Klinefelter patients. Human Reproduct 2009;24(9):2353-2360. DOI: 10.1093/humrep/ dep180.

10. Fullerton G, Hamilton M, Maheshwari A. Should non-mosaic Klinefelter syndrome men be labelled as infertile in 2009? Human Reproduct 2010;25(3):588-597. DOI: 10.1093/humrep/dep431.

11. Greco E, Scarselli F, Minasi MG, et al. Birth of 16 healthy children after ICSI in cases of nonmosaic Klinefelter syndrome. Human Reproduct 2013;28(5):1155-1160. DOI: 10.1093/humrep/det046.

12. Staessen C. PGD in 47, XXY Klinefelter's syndrome patients. Human Reproduct Update 2003;9(4):319-330. DOI: 10.1093/humupd/ dmg029.

13. Bojesen A, Stochholm K, Juul S, et al. Socioeconomic trajectories affect mortality in Klinefelter syndrome. J Clin Endocrinol Metabol 2011;96(1):2098-2104. DOI: 10.1210/jc.2011-0367. 